\title{
Usefulness of Atherectomy in Chronic Total Occlusion Interventions (from the PROGRESS-CTO Registry)
}

Iosif Xenogiannis, $\mathrm{MD}^{\mathrm{a}}$, Dimitri Karmpaliotis, $\mathrm{MD}, \mathrm{PhD}^{\mathrm{b}}$, Khaldoon Alaswad, $\mathrm{MD}^{\mathrm{c}}$, Farouc A. Jaffer, MD, PhD ${ }^{\mathrm{d}}$, Robert W. Yeh, MD ${ }^{\mathrm{e}}$, Mitul Patel, $\mathrm{MD}^{\mathrm{f}}$, Ehtisham Mahmud, $\mathrm{MD}^{\mathrm{f}}$, James W. Choi, MD ${ }^{\mathrm{g}}$, M. Nicholas Burke, MD ${ }^{\mathrm{a}}$, Anthony H. Doing, MD ${ }^{\mathrm{h}}$, Phil Dattilo, MD ${ }^{\mathrm{h}}$, Catalin Toma, MD ${ }^{\mathrm{i}}$, A.J. Conrad Smith, MD ${ }^{\mathrm{i}}$, Barry Uretsky, MD ${ }^{\mathrm{j}}$, Oleg Krestyaninov, MD ${ }^{\mathrm{k}}$, Dmitrii Khelimskii, MD ${ }^{\mathrm{k}}$, Elizabeth Holper, MD ${ }^{1}$, Srinivas Potluri, MD ${ }^{1}, \mathrm{R}$. Michael Wyman, $\mathrm{MD}^{\mathrm{m}}$, David E. Kandzari, $\mathrm{MD}^{\mathrm{n}}$, Santiago Garcia, $\mathrm{MD}^{\mathrm{o}}$, Michalis Koutouzis, $\mathrm{MD}^{\mathrm{p}}$, Ioannis Tsiafoutis, $\mathrm{MD}^{\mathrm{p}}$, Jaikirshan J. Khatri, $\mathrm{MD}^{\mathrm{q}}$, Wissam Jaber, MD ${ }^{\mathrm{r}}$, Habib Samady, MD ${ }^{\mathrm{r}}$, Brian K. Jefferson, $\mathrm{MD}^{\mathrm{s}}$, Taral Patel, MD ${ }^{\mathrm{s}}$, Jeffrey W. Moses, MD ${ }^{\mathrm{b}}$, Nicholas J. Lembo, MD ${ }^{\mathrm{b}}$, Manish Parikh, MD ${ }^{\mathrm{b}}$, Ajay J. Kirtane, MD ${ }^{\mathrm{b}}$, Ziad A. Ali, MD ${ }^{\mathrm{b}}$, Darshan Doshi, MD ${ }^{\mathrm{b}}$, Peter Tajti, MD ${ }^{\mathrm{a}, \mathrm{t}}$, Bavana V. Rangan, BDS, MPH ${ }^{\mathrm{a}}$, Shuaib Abdullah, MD ${ }^{\mathrm{u}}$, Subhash Banerjee, MD ${ }^{\mathrm{u}}$, and Emmanouil S. Brilakis, MD, PhD ${ }^{\mathrm{a}, *}$

There is limited data on the use of atherectomy during chronic total occlusion (CTO) percutaneous coronary intervention (PCI). We compared the clinical and procedural characteristics and outcomes of CTO PCIs performed with or without atherectomy in a contemporary multicenter CTO PCI registry. Between 2012 and 2018, 3,607 CTO PCIs were performed at 21 participating centers. Atherectomy was used in $117(3.2 \%)$ cases: rotational atherectomy in 105 cases, orbital atherectomy in 8 , and both in 4 cases. Patients in whom atherectomy was used, were older $(68 \pm 8$ vs $64 \pm 10$ years, $p<0.0001)$ and had higher Japan-chronic total occlusion score $(3.0 \pm 1.2$ vs $2.4 \pm 1.3, \mathrm{p}<0.0001)$. CTO PCI cases in which atherectomy was used had similar technical $(91 \%$ vs $87 \%, p=0.240)$ and procedural $(90 \%$ vs $85 \%, p=0.159)$ success and in-hospital major adverse cardiac event $(4 \%$ vs $3 \%, p=0.382)$ rates. However, atherectomy cases were associated with higher rates of donor vessel injury ( $4 \% \mathrm{vs} 1 \%, p=0.031)$, tamponade requiring pericardiocentesis $(2.6 \% \mathrm{vs} 0.4 \%, p=0.012)$ and more often required use of a left ventricular assist device $(9 \%$ vs $5 \%, p=0.031)$. Atherectomy cases were associated with longer procedural duration $(196[141,247]$ vs $119[76,180]$ minutes, $p<0.0001)$, and higher patient air kerma radiation dose $(3.6[2.5,5.6]$ vs $2.8[1.6,4.7]$ Gray, $p=0.001)$. In conclusion, atherectomy is currently performed in approximately $3 \%$ of CTO PCI cases and is associated with similar technical and procedural success and overall major adverse cardiac event rates, but higher risk for donor vessel injury and tamponade. () 2019 Elsevier Inc. All rights reserved. (Am J Cardiol 2019;123:1422-1428)

Balloon uncrossable CTOs (6\% to $9 \%$ of all CTOs) are lesions that cannot be crossed with a balloon after successful guidewire crossing, while balloon undilatable CTOs (12\% of all CTOs) are CTOs that cannot be expanded despite high-pressure balloon inflations, ${ }^{1-5}$ Rotational and orbital atherectomy can be used during PCI for: (1) lesion preparation, (2) treatment of "balloon-uncrossable," and (3) treatment of "balloon-undilatable" lesions. ${ }^{6}$ This study describes the patient population and outcomes of atherectomy performed during CTO PCI.

\footnotetext{
${ }^{\mathrm{a}}$ Minneapolis Heart Institute, Abbott Northwestern Hospital, Minneapolis, Minnesota; ${ }^{\mathrm{b}}$ Columbia University, New York, New York; ${ }^{\mathrm{c}} \mathrm{Henry}$ Ford Hospital, Detroit, Michigan; ${ }^{\mathrm{d}}$ Massachusetts General Hospital, Boston, Massachusetts; ${ }^{\mathrm{e}}$ Beth Israel Deaconess Medical Center, Boston, Massachusetts; ${ }^{\mathrm{f}} \mathrm{VA}$ San Diego Healthcare System and University of California San Diego, La Jolla, California; ${ }^{\mathrm{g}}$ Baylor Heart and Vascular Hospital, Dallas, Texas; ${ }^{\mathrm{h}}$ Medical Center of the Rockies, Loveland, Colorado; ${ }^{i}$ University of Pittsburgh Medical Center, Pittsburgh, Pennsylvania; ${ }^{j}$ VA Central Arkansas Healthcare System, Little Rock, Arkansas; ${ }^{\mathrm{k}}$ Meshalkin Novosibrisk Research Institute, Novosibirsk, Russia; ${ }^{1}$ The Heart Hospital Baylor Plano, Plano, Texas; ${ }^{\mathrm{m}}$ Torrance Memorial Medical Center, Torrance, California; ${ }^{\mathrm{n} P i e d m o n t ~ H e a r t ~ I n s t i t u t e, ~ A t l a n t a, ~ G e o r g i a ; ~}{ }^{\circ}$ VA Minneapolis Healthcare System and University of Minnesota, Minneapolis, Minnesota; ${ }^{\mathrm{p} R e d}$ Cross Hospital of Athens, Athens, Greece; ${ }^{\mathrm{q}}$ Cleveland Clinic, Cleveland, Ohio; ${ }^{\mathrm{r}}$ Emory University Hospital Midtown, Atlanta, Georgia; ${ }^{\mathrm{s}}$ Tristar Centennial Medical Center, Nashville, Tennesse; ${ }^{\mathrm{t}}$ Division of Invasive Cardiology, Second Department of Internal Medicine and Cardiology Center, University of Szeged, Szeged, Hungary; and "VA North Texas Health Care System and University of Texas Southwestern Medical Center, Dallas, Texas. Manuscript received September 12, 2018; revised manuscript received and accepted January 22, 2019.

Funding Sources: The Progress CTO registry has received support from the Abbott Northwestern Hospital Foundation, Minneapolis, MN.

See page 1427 for disclosure information.

*Corresponding author: Tel: 612-863-4204.

E-mail addresses: esbrilakis@gmail.com; esbrilakis@yahoo.com (E.S. Brilakis).
} 


\section{Methods}

Between January 2012 and May 2018, 3,607 CTO PCI cases were performed in 3,540 patients at 21 centers in the United States, Europe, and Russia and were included in the PROGRESS-CTO registry (Prospective Global Registry for the Study of Chronic Total Occlusion Intervention, NCT02061436). Rotational atherectomy (RA), orbital atherectomy or both, were used in 117 cases in 116 patients (3.2\% of cases). We compared the clinical, angiographic, and procedural characteristics and outcomes of CTO PCI cases performed with versus without atherectomy. The

Table 1

Clinical characteristics of the study patients, classified according to whether atherectomy was used

\begin{tabular}{|c|c|c|c|}
\hline $\begin{array}{l}\text { Atherectomy } \\
\text { Variable }\end{array}$ & Yes $(n=116)$ & No $(n=3,424)$ & $\mathrm{p}$ value \\
\hline Age (years)* & $68 \pm 8$ & $64 \pm 10$ & $<0.0001$ \\
\hline Men & $87 \%$ (99) & $85 \%(2511)$ & 0.5615 \\
\hline $\operatorname{BMI}\left(\mathrm{kg} / \mathrm{m}^{2}\right)^{*}$ & $32 \pm 7$ & $31 \pm 6$ & 0.0982 \\
\hline Smoker (current) & $13 \%(14)$ & $27 \%(795)$ & 0.0006 \\
\hline Diabetes mellitus & $61 \%(69)$ & $41 \%(1219)$ & $<0.0001$ \\
\hline Dyslipidemia $^{\dagger}$ & $96 \%(110)$ & $90 \%(2659)$ & 0.0221 \\
\hline Hypertension $^{\ddagger}$ & $94 \%(107)$ & $90 \%(2648)$ & 0.1541 \\
\hline CAD presentation & & & 0.9673 \\
\hline STEMI & $1 \%(1)$ & $1 \%(32)$ & \\
\hline NSTEMI & $7 \%(7)$ & $6 \%(155)$ & \\
\hline Unstable angina pectoris & $18 \%(19)$ & $18 \%(483)$ & \\
\hline Stable angina pectoris & $66 \%(68)$ & $65 \%(1744)$ & \\
\hline $\begin{array}{l}\text { Symptoms unlikely } \\
\text { to be ischemic }\end{array}$ & $2 \%(2)$ & $3 \%(75)$ & \\
\hline No symptoms & $6 \%(6)$ & $8 \%(205)$ & \\
\hline Prior MI & $49 \%(54)$ & $47 \%(1353)$ & 0.7682 \\
\hline Heart failure & $36 \%(40)$ & $31 \%(885)$ & 0.2481 \\
\hline Prior valve procedure & $7 \%(8)$ & $3 \%(86)$ & 0.0136 \\
\hline Prior PCI & $70 \%(79)$ & $65 \%(2137)$ & 0.2452 \\
\hline Prior $\mathrm{CABG}$ & $48 \%(55)$ & $31 \%(1032)$ & 0.0001 \\
\hline Prior CVD & $15 \%(17)$ & $11 \%(332)$ & 0.2292 \\
\hline Prior PVD & $14 \%(16)$ & $15 \%(429)$ & 0.9390 \\
\hline Chronic lung disease & $17 \%(19)$ & $14 \%(416)$ & 0.4685 \\
\hline Baseline creatinine $(\mathrm{mg} / \mathrm{dL})^{\S}$ & $1.1(0.9,1.4)$ & $1.0(0.9,1.2)$ & 0.0774 \\
\hline Left ventricular EF* & $48 \pm 14(\%)$ & $50 \pm 13(\%)$ & 0.0844 \\
\hline
\end{tabular}

$\mathrm{BMI}=$ body mass index $; \mathrm{CABG}=$ coronary artery bypass graft surgery; $\mathrm{CAD}=$ coronary artery disease $\mathrm{CVD}=$ cerebrovascular disease $; \mathrm{EF}=$ ejection fraction; $\mathrm{MI}=$ myocardial infarction; NSTEMI = non-ST segment elevation myocardial infarction; $\mathrm{PCI}=$ percutaneous coronary intervention; $\mathrm{PVD}=$ peripheral vascular disease $;$ STEMI $=$ ST segment elevation myocardial infarction.

* Mean \pm standard deviation.

${ }^{\dagger}$ Dyslipidemia was defined as (National Cholesterol Education Program criteria): (1) Total cholesterol greater than $200 \mathrm{mg} / \mathrm{dl}(5.18 \mathrm{mmol} / \mathrm{L})$; or (2) LDL greater than or equal to $130 \mathrm{mg} / \mathrm{dl}(3.37 \mathrm{mmol} / \mathrm{L})$; or, (3) HDL less than $40 \mathrm{mg} / \mathrm{dl}(1.04 \mathrm{mmol} / \mathrm{L})$; or (4) for patients with known coronary artery disease LDL greater than $100 \mathrm{mg} / \mathrm{dl}(2.59 \mathrm{mmol} / \mathrm{L})$.

${ }^{\ddagger}$ Hypertension was defined as: (1) History of hypertension diagnosed and treated with medication, diet and/or exercise; (2) Previous documentation of blood pressure greater than $140 \mathrm{~mm} \mathrm{Hg}$ systolic and/or $90 \mathrm{~mm} \mathrm{Hg}$ diastolic for patients without diabetes or chronic kidney disease, or previous documentation of blood pressure greater than $130 \mathrm{~mm} \mathrm{Hg}$ systolic and/or $80 \mathrm{~mm} \mathrm{Hg}$ diastolic on at least two occasions for patients with diabetes or chronic kidney disease.

${ }^{\S}$ Median (interquartile range). study was approved by the institutional review board of each center.

Coronary CTOs were defined as coronary lesions with Thrombolysis in Myocardial Infarction grade 0 flow of at least 3 months duration. Estimation of the duration of occlusion was clinical, based on the first onset of angina, history of myocardial infarction (MI) in the target vessel territory, or comparison with a previous angiogram. Calcification was assessed by angiography as mild (spots), moderate (involving $\leq 50 \%$ of the reference lesion diameter) and severe (involving $>50 \%$ of the reference lesion diameter). Moderate proximal vessel tortuosity was defined as the presence of at least 2 bends $>70^{\circ}$ or 1 bend $>90^{\circ}$ and severe tortuosity as 2 bends $>90^{\circ}$ or 1 bend $>120^{\circ}$ in the CTO vessel. Proximal cap ambiguity was defined as inability to determine the exact location of the proximal cap of the occlusion, due to the presence of obscuring side branches or overlapping branches that could not be resolved despite multiple angiographic projections. Interventional collaterals were defined as collaterals considered amenable to crossing by a guidewire and a microcatheter by the operator. A procedure was defined as "retrograde" if an attempt was made to cross the lesion through a collateral vessel or bypass graft supplying the target vessel distal to the lesion. Antegrade dissection/re-entry was defined as antegrade PCI during which a guidewire was intentionally introduced into the subintimal space proximal to the lesion, or attempt for reentry into the distal true lumen following intentional or inadvertent subintimal guidewire or device crossing.

Technical success was defined as successful CTO revascularization with achievement of $<30 \%$ residual diameter stenosis within the treated segment and restoration of Thrombolysis in Myocardial Infarction grade 3 antegrade flow. Procedural success was defined as achievement of

Table 2

Angiographic characteristics of the study lesions, classified according to whether atherectomy was used

\begin{tabular}{|c|c|c|c|}
\hline $\begin{array}{l}\text { Atherectomy } \\
\text { Variable }\end{array}$ & $\begin{array}{c}\text { Yes } \\
(\mathrm{n}=117)\end{array}$ & $\begin{array}{c}\text { No } \\
(\mathrm{n}=3,490) \\
\end{array}$ & $\mathrm{p}$ value \\
\hline Target coronary vessel & & & 0.0068 \\
\hline Right & $50 \%(57)$ & $56 \%(1872)$ & \\
\hline Left circumflex & $15 \%(17)$ & $19 \%(653)$ & \\
\hline Left main & $2 \%(2)$ & $0 \%(8)$ & \\
\hline Left anterior descending & $33 \%(37)$ & $23 \%(786)$ & \\
\hline CTO length $(\mathrm{mm})^{*}$ & $25(15,40)$ & $30(15,40)$ & 0.1867 \\
\hline Vessel diameter $(\mathrm{mm})^{*}$ & $3.0(2.5,3.0)$ & $3.0(2.5,3.0)$ & 0.0694 \\
\hline Proximal cap ambiguity & $32 \%(32)$ & $35 \%(875)$ & 0.5933 \\
\hline Moderate/severe calcification & $95 \%(104)$ & $51 \%(1632)$ & $<0.0001$ \\
\hline Moderate/severe tortuosity & $51 \%(55)$ & $34 \%(1089)$ & 0.0003 \\
\hline Interventional collaterals & $58 \%(57)$ & $57 \%(1403)$ & 0.8818 \\
\hline J-CTO score ${ }^{\dagger}$ & $3.0 \pm 1.2$ & $2.4 \pm 1.3$ & $<0.0001$ \\
\hline PROGRESS-CTO score ${ }^{\dagger}$ & $1.3 \pm 1.0$ & $1.3 \pm 1.0$ & 0.6331 \\
\hline $\begin{array}{l}\text { PROGRESS-CTO } \\
\text { complications score }^{\dagger}\end{array}$ & $3.5 \pm 1.9$ & $3.0 \pm 1.9$ & 0.0210 \\
\hline
\end{tabular}

$\mathrm{CTO}=$ chronic total occlusion; $\mathrm{J}=\mathrm{Japan}$; PROGRESS-CTO $=$ Prospective Global Registry of Chronic Total Occlusion Interventions.

* Median (interquartile range).

${ }^{\dagger}$ Mean \pm standard deviation. 
technical success without any in-hospital major adverse cardiac events (MACE). In-hospital MACE included any of the following adverse events before hospital discharge: death, MI, recurrent symptoms requiring urgent repeat target vessel revascularization with PCI or coronary artery bypass graft surgery, tamponade requiring either pericardiocentesis or surgery, and stroke. MI was defined using the Third Universal Definition of Myocardial Infarction (type $4 \mathrm{MI})^{7}$ Donor vessel injury was defined as either iatrogenic dissection or thrombus formation in the donor vessel. The Japan-chronic total occlusion score was calculated as described by Morino et $\mathrm{al}^{8}{ }^{8}$ the PROGRESS-CTO score as described by Christopoulos et al, ${ }^{9}$ and the PROGRESSCTO Complications score as described by Danek et al. ${ }^{10}$

"Non-atherectomy group" included procedures that did not include atherectomy, whereas the "atherectomy group" included procedures in which either rotational or orbital atherectomy or both were used.

Categorical variables were expressed as percentages and were compared using Pearson's Chi-square test or 2-tail Fisher's exact test. Continuous variables were presented as mean \pm standard deviation or median (interquartile range) unless otherwise specified and were compared using $t$ test or Wilcoxon rank-sum test, as appropriate. All statistical analyses were performed with JMP 14.0 (SAS Institute, Cary, North Carolina). A 2-sided p value of 0.05 was considered statistically significant.

\section{Results}

Among the 3,607 CTO PCI cases performed during the study period, RA was used in 105 (2.9\%) cases, orbital
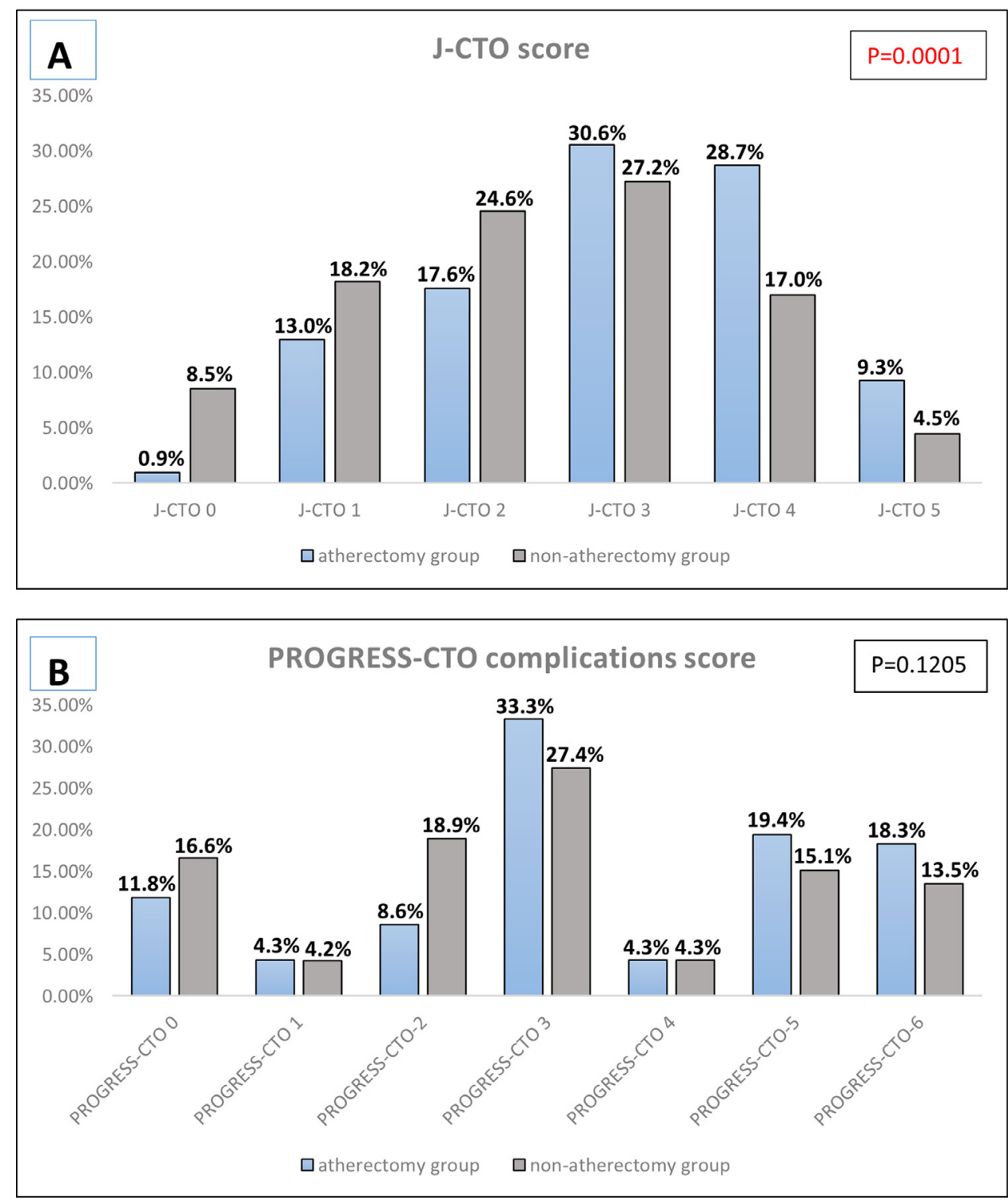

Figure 1. Panel A: J-CTO scores among the study patients, classified according to atherectomy use.

Panel B: PROGRESS-CTO complications score among the study patients, classified according to atherectomy use.

$\mathrm{J}-\mathrm{CTO}=$ Japan-chronic total occlusion; PROGRESS-CTO = Prospective Global Registry of Chronic Total Occlusion Interventions. 
Table 3

Technical characteristics of the study procedures, classified according to whether atherectomy was used

\begin{tabular}{lccc}
\hline $\begin{array}{l}\text { Atherectomy } \\
\text { Variable }\end{array}$ & Yes (n=117) & No (n=3,490) & p value \\
\hline $\begin{array}{l}\text { Vascular access } \\
\text { Femoral artery }\end{array}$ & $86 \%(101)$ & $79 \%(2763)$ & 0.0598 \\
Radial artery & $40 \%(47)$ & $40 \%(1400)$ & 0.9902 \\
Crossing strategies used & & & \\
AWE & $87 \%(102)$ & $82 \%(2871)$ & 0.1694 \\
ADR & $32 \%(37)$ & $30 \%(1051)$ & 0.7264 \\
Retrograde & $36 \%(42)$ & $37 \%(1308)$ & 0.7281 \\
Successful crossing strategies & & & 0.0085 \\
AWE & $59 \%(69)$ & $45 \%(1555)$ & \\
ADR & $12 \%(14)$ & $18 \%(617)$ & \\
Retrograde & $22 \%(26)$ & $23 \%(795)$ & \\
Unknown & $6 \%(7)$ & $13 \%(458)$ & \\
Collaterals used & & & \\
Septal & $21 \%(25)$ & $23 \%(806)$ & 0.6626 \\
Epicardial-contralateral & $9 \%(10)$ & $12 \%(412)$ & 0.2808 \\
Epicardial-ipsilateral & $1 \%(1)$ & $1 \%(21)$ & 1.0000 \\
SVG & $8 \%(9)$ & $5 \%(170)$ & 0.1669 \\
LIMA & $1 \%(1)$ & $1 \%(21)$ & 0.5169 \\
IVUS used for crossing & $6 \%(6)$ & $9 \%(219)$ & 0.2860 \\
Number of stents used & $3 \pm 1$ & $2 \pm 1$ & 0.0158 \\
\hline
\end{tabular}

$\mathrm{ADR}=$ antegrade dissection/re-entry; $\mathrm{AWE}=$ antegrade wire escalation; IVUS, intravascular ultrasound; LIMA, left internal mammary artery graft; SVG, saphenous vein graft.

* Mean \pm standard deviation.

atherectomy in $8(0.2 \%)$, and both in $4(0.1 \%)$ cases. In 51 cases $(1.4 \%)$ atherectomy was used for "balloonuncrossable" or/and "balloon-undilatable" lesions (bailout strategy) while in the remaining $66(1.8 \%)$ cases it was used for "lesion preparation" (planned strategy). The baseline clinical and angiographic characteristics of the study patients and lesions are summarized in Table 1 and Table 2. Patients in the atherectomy group were on average 3.7 years older and had more co-morbidities. Atherectomy-treated CTOs were more complex with higher risk for complications, as illustrated in Figure 1 and Table 2.

The CTO PCI techniques and outcomes are described in Table 3 and the procedural outcomes and complications are outlined in Table 4 . There was no difference among the study groups in technical, procedural success, and MACE.
However, the incidence of perforation (10\% vs $4 \%$, $\mathrm{p}=0.002)$, donor vessel injury ( $4 \%$ vs $1 \%, \mathrm{p}=0.031)$ and tamponade requiring pericardiocentesis $(2.6 \%$ vs $0.4 \%$, $\mathrm{p}=0.012$ ) were higher in the atherectomy group. On multivariable analysis, the only factor that was associated independently with MACE was proximal cap ambiguity (Figure 2). If perforation and donor vessel injury were included in the composite end point of MACE, MACE rate was higher in the atherectomy group (14\% vs $7 \%, \mathrm{p}=0.005)$, but procedural success remained similar between the 2 groups ( $82 \%$ vs $80 \%, p=0.576$ ). Left ventricular assist devices were utilized more frequently in the atherectomy group (9\% vs $5 \%$, $\mathrm{p}=0.031$ ).

Cases in which atherectomy was used as a bail-out strategy had similar technical $(92 \%$ vs $89 \%, \mathrm{p}=0.754)$ and procedural $(90 \%$ vs $89 \%, p=0.850)$ success, but numerically higher in-hospital MACE rates $(7 \%$ vs $2 \%$, $\mathrm{p}=0.367$ ) compared with cases in which atherectomy was planned. "Balloon-uncrossable" and "balloon-undilatable" lesions treated with atherectomy had higher technical (92\% vs 79\%, p $=0.032)$ and procedural $(90 \%$ vs $79 \%$, $\mathrm{p}=0.046)$ success and similar MACE rates $(7 \%$ vs $4 \%$, $\mathrm{p}=0.422)$ as compared with similar lesions not treated with atherectomy.

\section{Discussion}

The main findings of our study are that atherectomy (RA in most cases): (1) is currently used infrequently during CTO PCI mainly for complex lesions, (2) is associated with similar technical success, but (3) higher risk for donor vessel injury and tamponade requiring pericardiocentesis.

There is wide variability in atherectomy use during CTO PCI, ranging from $3.5 \%$ to $9 \%$ (Table 5), likely due to variations in equipment availability and operator expertise. In our study, atherectomy use decreased during the last 3 years (Figure 3), possibly due to high rates of retrograde and antegrade dissection re-entry techniques.

In nearly all atherectomy cases, successful guidewire crossing preceded atherectomy. After excluding failed crossing cases and cases when the successful crossing technique was unknown, atherectomy was associated with lower technical success rates compared with the nonatherectomy group (95\% vs $98 \%, \mathrm{p}=0.004)$. However, procedural success $(94 \%$ vs $96 \%, \mathrm{p}=0.358)$ and MACE

Table 4

Procedural outcomes among patients who underwent retrograde CTO PCI, classified according to whether atherectomy was used

\begin{tabular}{lccr}
\hline $\begin{array}{l}\text { Atherectomy } \\
\text { Variable }\end{array}$ & $\begin{array}{c}\text { Yes } \\
(\mathrm{n}=116)\end{array}$ & \multicolumn{1}{c}{ No } \\
$(\mathrm{n}=3,424)$ & $\mathrm{p}$ value \\
\hline Technical success & $91 \%(106)$ & $87 \%(3032)$ & 0.2391 \\
Procedural success & $90 \%(104)$ & $85 \%(2695)$ & 0.1588 \\
Procedural complications & $21 \%(24)$ & $10 \%(292)$ & 0.0001 \\
Procedure time (min)* & $196(141,247)$ & $260(195,180)$ & $<0.0001$ \\
Contrast volume $(\mathrm{mL}) *$ & $233(177,320)$ & $45.50(27.00,74.59)$ & 0.1085 \\
Fluoroscopy time (min)* & $77.75(45.70,104.75)$ & $2.78(1.56,4.65)$ & $<0.0001$ \\
Patient AK dose (Gray)* & $3.57(2.48,5.56)$ & $3 \%(95)$ & 0.0012 \\
In-hospital MACE & $4 \%(5)$ & & 0.3818 \\
\hline
\end{tabular}

$\mathrm{AK}=$ air kerma; $\mathrm{MACE}=$ in-hospital major adverse cardiovascular events.

* Median (interquartile range). 
Table 5

Previous studies evaluating the use of atherectomy in CTO interventions

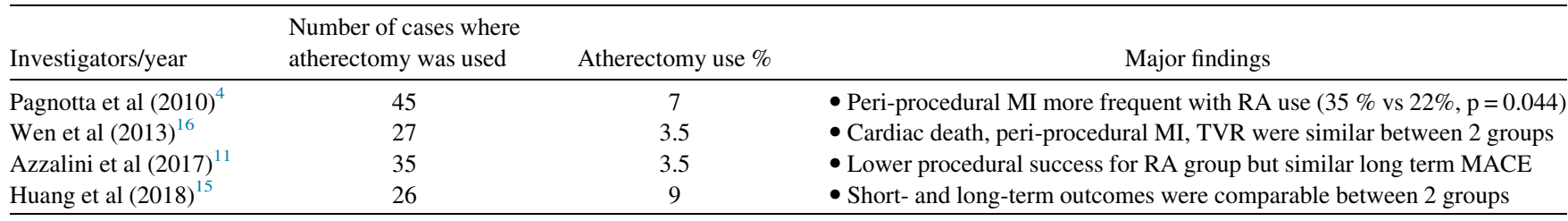

$\mathrm{CTO}=$ chronic total occlusion MACE $=$ major adverse cardiac events $; \mathrm{MI}=$ myocardial infarction $; \mathrm{PCI}=$ percutaneous coronary intervention $; \mathrm{RA}=$ rota tional atherectomy; TVR = target vessel revascularization.

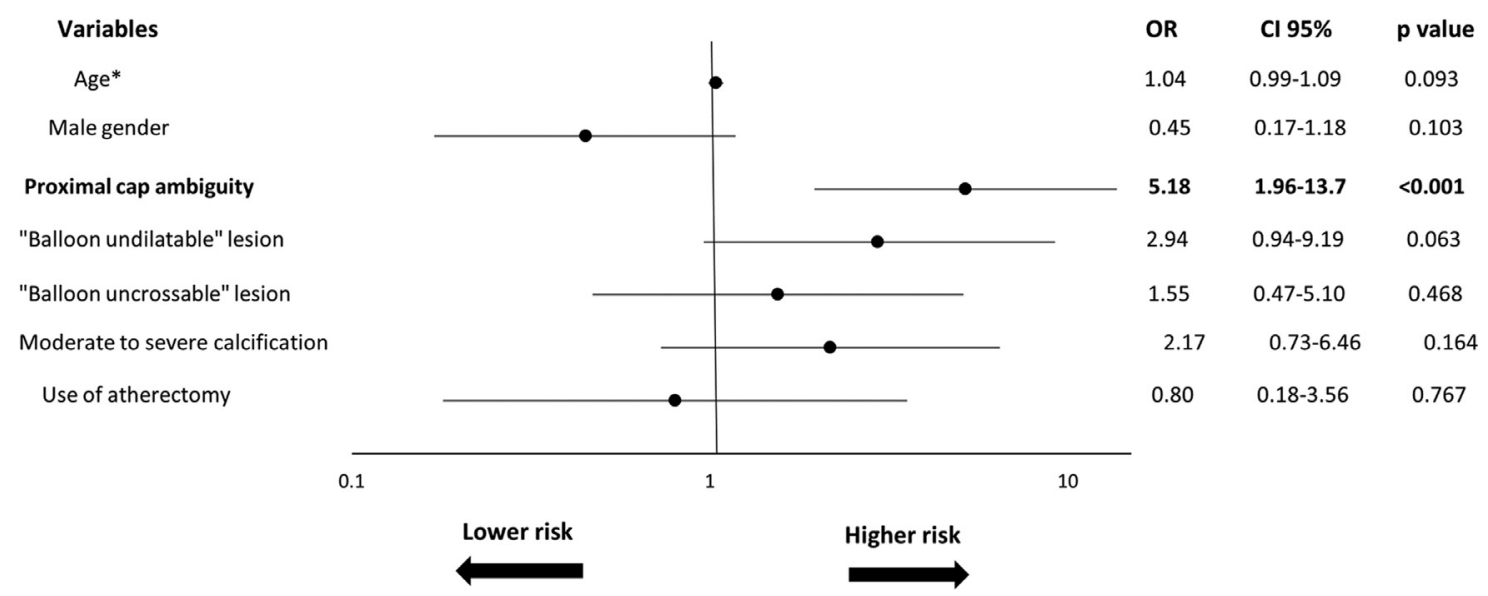

Figure 2. Multivariable logistic regression of baseline clinical and angiographic characteristics for in-hospital major adverse cardiac events in patients who underwent CTO PCI. *Per 1 unit (year) change.

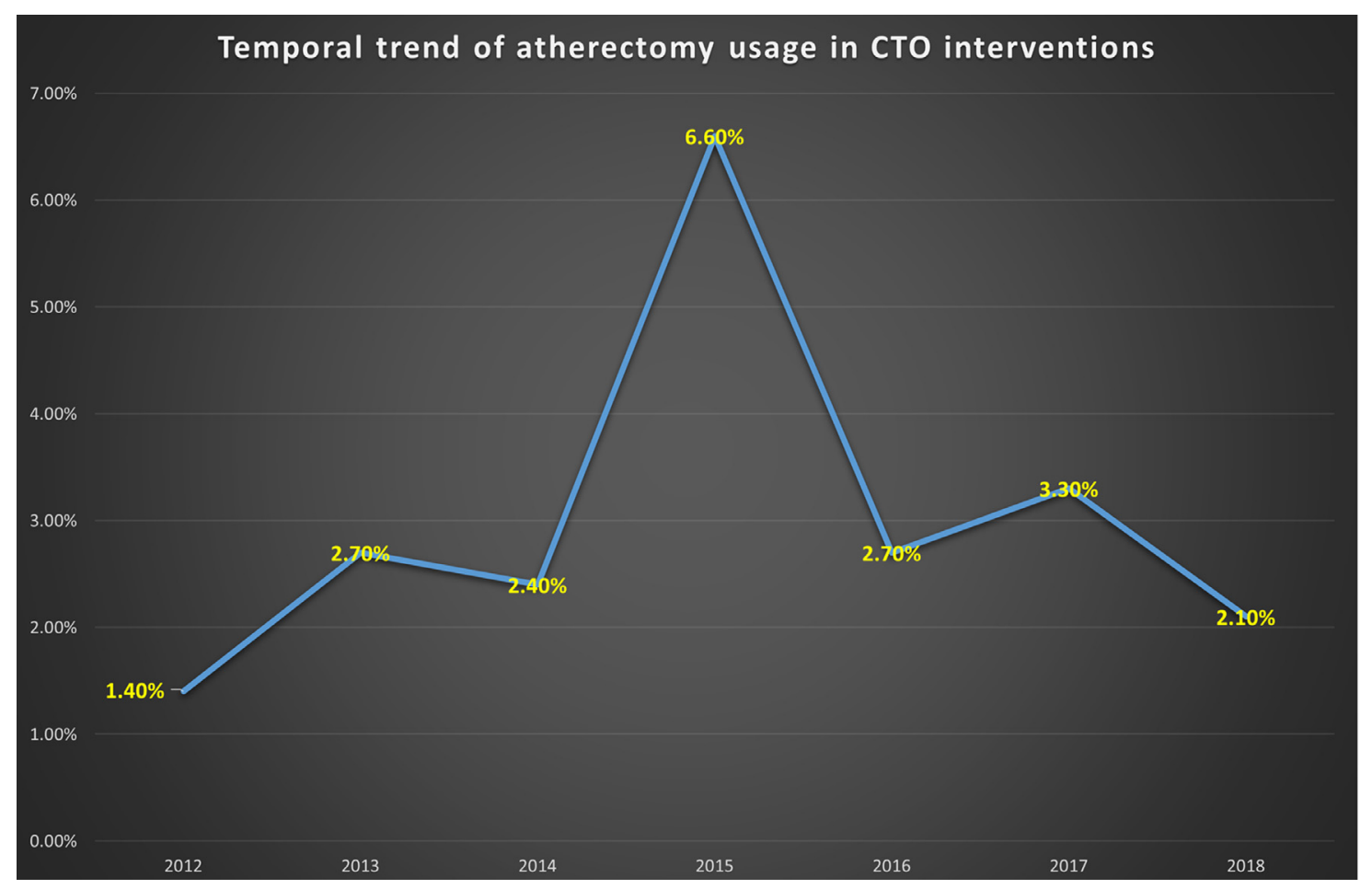

Figure 3. Temporal trend in atherectomy use for chronic total occlusion interventions. 
$(5 \%$ vs $3 \%, p=0.195)$ rates were similar. In previous studies, atherectomy cases had similar or better success rates than nonatherectomy cases with the exception of a study by Azzalini et al that reported lower procedural success with RA $(77 \%$ vs $89 \%, p=0.04) .{ }^{11}$ More than half of the atherectomy cases in our study had moderate or severe proximal vessel tortuosity, even though tortuosity is often considered a relative contraindication to performing atherectomy. ${ }^{12}$

Atherectomy is known to have higher risk for perforation in non-CTO cases. ${ }^{13-14}$ In a study of 35 patients who underwent RA during CTO PCI by Azzalini et al the following RA-associated complications were reported: 6 $(17 \%)$ cases of slow/no reflow, $6(17 \%)$ cases of bradyarrhythmia, and 10 (29\%) cases of dissection. During a mean follow-up of $658 \pm 412$ days, MACE rates were similar in RA and non-RA cases $(15 \%$ vs $13 \%, p=0.7) .{ }^{11}$ In a study by Pagnotta et al, none of the patients in the atherectomy group experienced coronary perforation whereas in the conventional group 3 patients suffered a coronary perforation. ${ }^{4}$ Huang et al reported only 1 major complication associated with the use of RA utilization (a coronary perforation needing emergent surgical intervention of $26 \mathrm{RA}$ cases). ${ }^{15}$

Coronary atherectomy has disadvantages: it can be time consuming, increases the cost of the procedure, and carries risk for complications, such as perforation, dissection, bradyarrhythmias, and burr/crown entrapment. ${ }^{11}$ Atherectomy remains an indispensable tool for complex CTO and nonCTO PCI, but it should be used by experienced operators and with caution.

Our study has important limitations. First, it was an observational retrospective study without long-term follow-up. Second, there was no standard protocol regarding use of atherectomy, which was performed at the operator discretion. Third, the number of patients who were treated with atherectomy was relatively small (116 patients, approximately $3 \%$ of the total population) and the comparison group had lower angiographic and clinical complexity. Fourth, due to the large number of operators, there is possibility of reporting bias. Fifth, there was no core laboratory assessment of the study angiograms or clinical event adjudication. Sixth, in the vast majority of our cases RA was used, limiting conclusions regarding orbital atherectomy. Finally, the procedures were performed in dedicated, high volume CTO centers by experienced operators, limiting the extrapolation to less experienced operators and lower volume centers.

\section{Disclosures}

Dr. Xenogiannis: nothing to disclose.

Dr. Karmpaliotis: speaker honoraria: Abbott Vascular, Boston Scientific, Medtronic, Vascular Solutions.

Dr. Alaswaad: consulting fees from Terumo and Boston Scientific; consultant, no financial, Abbott Laboratories.

Dr. Jaffer: consultant: Abbott Vascular, Boston Scientific and Siemens. Research grant: Canon, Siemens and National Institutes of Health.

Dr. Yeh: career development award (1K23HL118138) from the National Heart, Lung, and Blood Institute.

Dr. M. Patel: speakers' bureau for Astra Zeneca.

Dr. Mahmud: consulting fees from Medtronic and Corindus; speaker's fees from Medtronic, Corindus, and Abbott
Vascular; educational program fees from Abbott Vascular; and clinical events committee fees from St. Jude.

Dr. Choi: nothing to disclose.

Dr. Burke: consulting and speaker honoraria from Abbott Vascular and Boston Scientific.

Dr. Doing: nothing to disclose.

Dr. Datillo: nothing to disclose

Dr. Toma: nothing to disclose.

Dr. Smith: nothing to disclose.

Dr. Uretsky: nothing to disclose.

Dr. Krestyaninov: nothing to disclose.

Dr. Khelimskii: nothing to disclose.

Dr. Holper: nothing to disclose.

Dr. Potluri: nothing to disclose.

Dr. Wyman: speakers bureau: Boston Scientific, Abbott Vascular, and Asahi. Honoraria: Boston Scientific, Abbott Vascular, and Asahi. Consultant/Advisory Board: Boston Scientific, Abbott Vascular, and Asahi.

Dr. Kandzari: research grant: Boston Scientific and Medtronic Cardiovascular, Abbott. Consultant/Advisory Board: Boston Scientific and Medtronic Cardiovascular.

Dr. Garcia: consulting fees from Medtronic.

Dr. Koutouzis: nothing to disclose.

Dr. Tsiafoutis: nothing to disclose.

Dr. Khatri: research grant support: Asahi Intecc. Speaker/Proctor: Abbott Vascular

Dr. Jaber: nothing to disclose.

Dr. Samady: nothing to disclose.

Dr. Jefferson: honoraria/consulting/speaking fees from Abbott, Boston Scientific, CSI, Medtronic.

Dr. T. Patel: nothing to disclose.

Dr. Moses: consultant to Boston Scientific and Abiomed.

Dr. Lembo: speaker bureau: Medtronic. Consultant/ Advisory Board: Abbott Vascular and Medtronic.

Dr. Parikh: speaker bureau: Abbot Vascular, Medtronic, CSI, BSC, Trireme; advisory boards: Medtronic, Abbott Vascular, Philips.

Dr. Kirtane: Institutional research grants to Columbia University from Boston Scientific, Medtronic, Abbott Vascular, Abiomed, St. Jude Medical, Vascular Dynamics, Glaxo SmithKline, and Eli Lilly.

Dr. Ali: consultant fees/honoraria from St. Jude Medical, and AstraZeneca Pharmaceuticals; ownership interest/partnership/principal in Shockwave Medical and VitaBx Inc; and research grants from Medtronic and St. Jude Medical.

Dr. Doshi: nothing to disclose.

Dr. Tajti: nothing to disclose.

Dr. Rangan: research grants from InfraReDx, Inc., and The Spectranetics Corporation.

Dr. Abdullah: nothing to disclose.

Dr. Banerjee: research grants from Gilead and the Medicines Company; consultant/speaker honoraria from Covidien and Medtronic; ownership in MDCARE Global (spouse); intellectual property in HygeiaTel.

Dr. Brilakis: consulting/speaker honoraria from Abbott Vascular, American Heart Association (associate editor Circulation), Boston Scientific, Cardiovascular Innovations Foundation (Board of Directors), CSI, Elsevier, GE Healthcare, InfraRedx, and Medtronic; research support from Siemens, and Regeneron. Shareholder: MHI Ventures. Board 
of Trustees: Society of Cardiovascular Angiography and Interventions

\section{Acknowledgments}

Study data were collected and managed using Research Electronic Data Capture (REDCap) electronic data capture tools hosted at the Minneapolis Heart Institute Foundation (MHIF), Minneapolis, Minnesota. REDCap is a secure, web-based application designed to support data capture for research studies, providing: (1) an intuitive interface for validated data entry, (2) audit trails for tracking data manipulation and export procedures, (3) automated export procedures for seamless data downloads to common statistical packages, and (4) procedures for importing data from external sources.

1. Karacsonyi J, Karmpaliotis D, Alaswad K, Jaffer FA, Yeh RW, Patel M, Bahadorani J, Doing A, Ali ZA, Karatasakis A, Danek BA, Rangan BV, Alame AJ, Banerjee S, Brilakis ES. Prevalence, indications and management of balloon uncrossable chronic total occlusions: insights from a contemporary multicenter US registry. Catheter Cardiovasc Interv 2017;90:12-20.

2. Kovacic JC, Sharma AB, Roy S, Li JR, Narayan R, Kim DB, Sharma SK, Kini AS. GuideLiner mother-and-child guide catheter extension: a simple adjunctive tool in PCI for balloon uncrossable chronic total occlusions. J Interv Cardiol 2013;26:343-350.

3. Patel SM, Pokala NR, Menon RV, Kotsia AP, Raja V, Christopoulos G, Michael TT, Rangan BV, Sherbet D, Patel VG, Abdullah SA, Hastings J, Grodin JM, Banerjee S, Brilakis ES. Prevalence and treatment of "balloon-uncrossable" coronary chronic total occlusions. J Invasive Cardiol 2015;27:78-84.

4. Pagnotta P, Briguori C, Mango R, Visconti G, Focaccio A, Belli G, Presbitero P. Rotational atherectomy in resistant chronic total occlusions. Catheter Cardiovasc Interv 2010;76:366-371.

5. Tajti P, Karmpaliotis D, Alaswad K, Toma C, Choi JW, Jaffer FA, Doing AH, Patel M, Mahmud E, Uretsky B, Karatasakis A, Karacsonyi J, Danek BA, Rangan BV, Banerjee S, Ungi I, Brilakis ES. Prevalence, presentation and treatment of 'Balloon Undilatable' Chronic Total Occlusions: insights from a Multicenter US Registry. Catheter Cardiovasc Interv 2018;91:657-666.

6. Brilakis ES. Manual of Chronic Total Occlusion Interventions a Stepby-Step Approach. London: Elsevier/Academic Press; 2018. p. xviii..

7. Thygesen K, Alpert JS, Jaffe AS, Simoons ML, Chaitman BR, White HD, Joint ESCAAHAWHFTFfUDoMIAuthors/Task Force Members CThygesen K, Alpert JS, White HD, Biomarker S, Jaffe AS, Katus HA, Apple FS, Lindahl B, Morrow DA, Subcommittee ECGChaitman BR, Clemmensen PM, Johanson P, Hod H, Imaging S, Underwood R, Bax JJ, Bonow JJ, Pinto F, Gibbons RJ, Classification SFox KA, Atar D, Newby LK, Galvani M, Hamm CW, Intervention S, Uretsky BF, Steg PG, Wijns W, Bassand JP, Menasche P, Ravkilde J, Trials, Registries SOhman EM, Antman EM, Wallentin LLC, Armstrong PPW, Simoons ML, Trials, Registries SJanuzzi JL, Nieminen MS, Gheorghiade M, Filippatos G, Trials, Registries SLuepker RV, Fortmann SP,
Rosamond WD, Levy D, Wood D, Trials, Registries SSmith SC, Hu D, Lopez-Sendon JL, Robertson RM, Weaver D, Tendera M, Bove AA, Parkhomenko AN, Vasilieva EJ, Mendis S, Guidelines ESCCfPBax JJ, Baumgartner H, Ceconi C, Dean V, Deaton C, Fagard R, Funck-Brentano C, Hasdai D, Hoes A, Kirchhof P, Knuuti J, Kolh P, McDonagh T, Moulin C, Popescu BA, Reiner Z, Sechtem U, Sirnes PA, Tendera M, Torbicki A, Vahanian A, Windecker S, Document RMorais J, Aguiar C, Almahmeed W, Arnar DO, Barili F, Bloch KD, Bolger AF, Botker HE, Bozkurt B, Bugiardini R, Cannon C, de Lemos J, Eberli FR, Escobar E, Hlatky M, James S, Kern KB, Moliterno DJ, Mueller C, Neskovic AN, Pieske BM, Schulman SP, Storey RF, Taubert KA, Vranckx P, Wagner DR. Third universal definition of myocardial infarction. J Am Coll Cardiol 2012;60:1581-1598.

8. Morino Y, Abe M, Morimoto T, Kimura T, Hayashi Y, Muramatsu T, Ochiai M, Noguchi Y, Kato K, Shibata Y, Hiasa Y, Doi O, Yamashita T, Hinohara T, Tanaka H, Mitsudo K, Investigators JCR. Predicting successful guidewire crossing through chronic total occlusion of native coronary lesions within 30 minutes: the J-CTO (Multicenter CTO Registry in Japan) score as a difficulty grading and time assessment tool. JACC Cardiovasc Interv 2011;4:213-221.

9. Christopoulos G, Kandzari DE, Yeh RW, Jaffer FA, Karmpaliotis D, Wyman MR, Alaswad K, Lombardi W, Grantham JA, Moses J, Christakopoulos G, Tarar MN, Rangan BV, Lembo N, Garcia S, Cipher D, Thompson CA, Banerjee S, Brilakis ES. Development and validation of a novel scoring system for predicting technical success of chronic total occlusion percutaneous coronary interventions: the PROGRESS CTO (Prospective Global Registry for the Study of Chronic Total Occlusion Intervention) Score. JACC Cardiovasc Interv 2016;9:1-9.

10. Danek BA, Karatasakis A, Karmpaliotis D, Alaswad K, Yeh RW, Jaffer FA, Patel MP, Mahmud E, Lombardi WL, Wyman MR, Grantham JA, Doing A, Kandzari DE, Lembo NJ, Garcia S, Toma C, Moses JW, Kirtane AJ, Parikh MA, Ali ZA, Karacsonyi J, Rangan BV, Thompson CA, Banerjee S, Brilakis ES. Development and validation of a scoring system for predicting periprocedural complications during percutaneous coronary interventions of Chronic Total Occlusions: the Prospective Global Registry for the Study of Chronic Total Occlusion Intervention (PROGRESS CTO) Complications Score. J Am Heart Assoc 2016: 5. pii: JAHA.116.004272.

11. Azzalini L, Dautov R, Ojeda S, Serra A, Benincasa S, Bellini B, Giannini F, Chavarria J, Gheorghe LL, Pan M, Carlino M, Colombo A, Rinfret S. Long-term outcomes of rotational atherectomy for the percutaneous treatment of chronic total occlusions. Catheter Cardiovasc Interv 2017;89:820-828.

12. Tomey MI, Kini AS, Sharma SK. Current status of rotational atherectomy. JACC Cardiovasc Interv 2014;7:345-353.

13. Gunning MG, Williams IL, Jewitt DE, Shah AM, Wainwright RJ, Thomas MR. Coronary artery perforation during percutaneous intervention: incidence and outcome. Heart 2002;88:495-498.

14. Uetani T, Amano T. Current status of rotational atherectomy in the Drug-Eluting Stent Era. Circ J 2018;82:946-947.

15. Huang WC, Teng HI, Chan WL, Lu TM. Short-term and long-term clinical outcomes of rotational atherectomy in resistant chronic total occlusion. J Interv Cardiol 2018;31:458-464.

16. Wen SY, Yu HY, Wang BY, Sun ZQ, Wang MQ, Liu SQ, Li H. Feasibility and outcome of rotational atherectomy for treating resistant chronic total occlusions. Zhonghua xin xue guan bing za zhi 2013;41: $466-469$. 